Original Article

\title{
PREVALENCE OF EXCLUSIVE BREASTFEEDING AMONG MOTHERS OF INFANTS AGED 0-6 MONTHS IN MAKURDI, NIGERIA: A CROSS-SECTIONAL SURVEY
}

Egwuda L. ${ }^{1}$ and Bako I.A. ${ }^{2}$

Department of Family Medicine, Benue State University Teaching Hospital ${ }^{l}$ and Department of Epidemiology and Community Health, College of Health Sciences, Benue State University ${ }^{2}$, Makurdi.

*Corresponding Author: Dr Livinus Egwuda, Department of Family Medicine, Benue State University Teaching Hospital. Email: docklevis@yahoo.com

Received date: April $9^{\text {th }} 2018$, Accepted date: June $5^{\text {th }} 2018$. Published date: June $30^{\text {th }} 2018$

\begin{abstract}
There is paucity of reports on breastfeeding practices among nursing mothers in Makurdi, Benue state. The study was aimed at determining the prevalence of exclusive breastfeeding and associated factors among mothers of infants aged 0-6months attending Child Welfare Clinics in Makurdi, Benue state. This cross-sectional study was conducted among 300 mothers of children aged 0-6months attending under-five clinics in Makurdi. Data was collected using structured questionnaire and analyzed using SPSS version 20. The mean age of the infants was 3.06 months \pm 2.2 months. Majority of the mothers 292(97.3\%) were currently breastfeeding, but less than half of the mothers $141(47.0 \%)$ were exclusively breastfeeding. Among mothers that were not practicing exclusive breastfeeding, 103(64.8\%) gave water, 68(42.8\%) administered soft drink, 54(34.0\%) gave infant formula, $11(6.9 \%)$ gave custard, while $17(10.7 \%)$ administered yam porridge, tea, fruit juice or liquid milk. Mothers who had one or more previous pregnancies and mothers of babies aged 0-1month were more likely to practice EBF. Even though the exclusive breastfeeding prevalence reported in this study is above the national figure, it is however less than the World Health Organization target for infants that are six months and below. Efforts should be intensified to sustain this giant stride with the hope of improving on it through public awareness on the importance of exclusive breastfeeding.
\end{abstract}

Keywords: Exclusive breastfeeding, infants, Mothers, Makurdi, Prevalence

\section{Introduction}

Nutrition especially at the early stages of life has continued to attract global attention. It is one of the most important factors that affect child survival, and development. ${ }^{1}$ Inappropriate and inadequate nutrition can negatively affect the quality of life of the child. As a result World Health Organization and United Nation International Children Fund came up with a noble policy of exclusive breastfeeding practice for the first six months of life. ${ }^{2}$ Exclusive breastfeeding is the practice of only giving an infant breast-milk for the first six months of life (no other food or water) and has the single largest potential impact on child mortality of any preventive intervention ${ }^{3}$. It is part of optimal breastfeeding practices, which also include initiation within one hour of life and continued breastfeeding for up to 2 years of age or beyond. ${ }^{3}$
The overwhelming benefits of exclusive breastfeeding to the infants, mothers and the environment have been established in many research publications. ${ }^{4,5,6}$ For instance, it has been shown to be a cornerstone of child survival and child health because it provides essential, irreplaceable nutrition for a child's growth and development. It serves as a child's first immunization - providing protection from respiratory infections ${ }^{7}$, diarrhoeal disease, and other potentially life-threatening ailments. Exclusive breastfeeding also has a protective effect against obesity and certain noncommunicable diseases later in life. ${ }^{7}$ Even though the policy on exclusive breastfeeding is now well over two decades, evidence from research has not shown encouraging trend especially in developing countries. For instance the global prevalence of exclusive 
breastfeeding was reported to be $38 \% .^{8,9}$ Similarly, publications of the International Baby Food Action Network (IBFAN) have shown that the exclusive breastfeeding at 3-4 months in different countries include Botswana to be $29.7 \%$, Eritrea 64\%, Ghana $36 \%$, Kenya $17 \%$, Lesotho 54\%, Malawi $11 \%$, Somali 7\%, Sudan 40.8\%, Swaziland 53\%, Tanzania $4.1 \%$, Uganda $68 \%$ and Zimbabwe $2.5 \% .^{10}$

In Nigeria, experts have described the rate of exclusive breastfeeding as being the worst in Africa. The Nigerian National Demographic and Health Survey (NDHS) reported in 2013 that only $13.1 \%$ of new born were exclusively breastfed ${ }^{11,12}$. This report is coming at a time when Ghana had achieved $63 \%$ exclusive breastfeeding rate between 2005-2007. ${ }^{13}$ Furthermore, a neighboring State to the study location reported a prevalence of $22.9 \% .^{14}$ Similarly, in different states of Nigeria, reports have shown wide variations ${ }^{15,16}$ in exclusive breastfeeding rate, with a significant number showing figures that were far below WHO recommendation of more than $50 \% .^{17,18}$

This discouraging prevalence of exclusive breastfeeding practice prompted some primary care experts to go in search of factors that are associated with exclusive breastfeeding with a view of fashioning out intervention programs to address them. Some of the factors identified to be associated with exclusive breastfeeding include socio-demographic factors (educational level, urban versus rural residence, monthly household income and parity); biosocial factors (breastfeeding support); cultural factors (beliefs, norms and attitudes towards breastfeeding), employment policies as well as maternal antenatal care history, place of delivery, and type of delivery, maternal parity, use of pre-lacteal feeds and use of bottle feeding. ${ }^{19,20,21,22,23}$

The prevalence of exclusive breastfeeding varies widely from one geographical region of the country to another based on differences in socio-cultural characteristics between these regions. No report has been documented about breastfeeding practices in Makurdi the capital city of Benue State. This study therefore sought to investigate the prevalence of exclusive breastfeeding; and to determine the associated factors among nursing mothers of infants aged 0-6months attending Child Welfare Clinics in Makurdi.

\section{Materials and Methods}

\section{Study setting}

This study was carried out in Makurdi the capital of Benue State; in North Central, Nigeria. It lies between latitude $7.73^{\circ}$ and longitude $8.32^{\circ}$ It has a population of about 300,377 people (NPC 2006). Majority of the people were traders and farmers.

The study was conducted in three major Child Welfare Clinics in Makurdi metropolis. These included the Child Welfare Clinics of the Benue State University Teaching Hospital, the State Epidemiology Unit, and the Family Support Clinic. These clinics were set up and mandated to among other things, monitor the growth of under-five children, administer routine immunization, health education including demonstrations and attend to minor ailments of children under-five years. A sample size of 271 mothers and infants was calculated using the exclusive breastfeeding rate of $22.9 \%{ }^{24}$ obtained from a previous study. However, 300 mother-infants pairs were recruited for the study.

\section{Study design}

It is a descriptive cross-sectional study to determine the prevalence of exclusive breastfeeding and the associated factors.

\section{Study population}

The study was conducted among 300 mothers of children 0-6months, visiting the under-five clinics in Makurdi, Benue State comprising Family Support Programme (FSP) Clinic, State Epidemiological Unit, and the Benue State Teaching Hospital.The inclusion criteria include subjects should be the biological mothers of the infants and the infants should be less than 6 months old.

\section{Sample size estimation}

The sample size was determined using the formula below. $^{25}$

$n=\frac{\left(Z_{1}-a\right)^{2} \quad P(1-P)}{d^{2}}$

Where:

$\mathrm{n}=$ Minimum sample size

$\mathrm{z}_{1-\mathrm{a}}=$ Constant at $95 \%$ confidence interval from two tables which is 1.96 for two tailed study. 


$\begin{aligned} \mathrm{P}= & \begin{array}{l}\text { Best estimate of population } \\ \text { prevalence obtained from literature } \\ \text { review, which is } 22.9 \% .^{14}\end{array} \\ \mathrm{~d}= & \begin{array}{l}\text { Precision which at } 95 \% \text { confidence } \\ \text { interval is } 5 \% .\end{array}\end{aligned}$

$n=\frac{(1.96)^{2} \times 0.229(1-0.229)}{(0.05)^{2}}=271$

Therefore, the minimum sample size was increased to 300 to accommodate invalid filled questionnaires.

\section{Sampling technique}

This study used a multi-stage sampling technique. There are five major Child Welfare Clinics in Makurdi: The Family Support Clinic, The State Epidemiology Clinic, Federal Medical Centre, General Hospital, North Bank, and the Benue State University Teaching Hospital. Three of the Clinics were selected by simple random sampling method. The clinics selected are the Family Support Clinic, State Epidemiology Unit, and the State University Teaching Hospital. The entire pair of mother and infants (0-6 months) who presented to these Child Welfare Clinics within the period of the study and consented to participate in the survey were selected consecutively until the sample size was obtained. The distribution of the samples to the various clinics was done in a proportionate manner based on the average number of babies seen routinely in each clinic.

\section{Data collection}

An interviewer administered, semi-structured and pretested questionnaire was used to collect data with the assistance of trained research assistants (Medical Students). The questionnaire obtained information on the mother's Sociodemographic and the other relevant variables. Data collection was done on clinic days between Mondays and Fridays. The research assistants had prior short training on interviewing skills, methodology of the study and ethical issues.

\section{Data analysis}

The filled questionnaires were examined for completeness and entered into spreadsheet and then exported to Statistical Package for Social Sciences (SPSS) version 20 for further cleaning and analysis. The main outcome variable was the practice of exclusive breastfeeding. The exposure variables include maternal age, educational attainment, and employment status, marital status number of previous deliveries, ante-natal care attendance, infant feeding counseling and place of delivery. Chi square test was used to test for association between the outcome and the exposure variables

\section{Ethical consideration}

Ethical approval for the study was obtained from the Ethical Review Committee of Benue State University Teaching Hospital, Makurdi. Written consent for the study was also obtained from the authorities of the other two clinics. Signed informed consent of the mothers was obtained after explaining the aims and objectives of the study and what their participation entails. In order to guarantee anonymity of each participant, the names of the respondents, addresses and identification information were excluded.

\section{Results}

\section{Socio-demographic characteristics}

A total of 300 mothers were recruited for the study. The infants were aged $0-6$ months with a mean age of 3.06 months and a standard deviation of 2.2 months. Majority of the infants were aged 1-3 months. The mother's mean age was 26.2 and standard deviation of 5.0.The socio-demographic profile of mothers showed that the majority of the subjects $165(55.0 \%)$ had secondary school education while $5(1.7 \%)$ had no formal education. Almost all the participants 291(97.0\%) were Christians, while Muslims were 9(3.0\%). The Tiv tribe accounted for the majority of the ethnic group 199(66.3\%) while the Igede were $5(1.7 \%)$.

On the occupation of the participants; farmers were 20(6.7\%), government employee 49(16.3\%), daily labour $9(3.0 \%)$, housewife $69(23.0 \%)$, skilled worker $22(7.3 \%)$, student $30(10.0 \%)$ and others were $6(2.0 \%)$. The currently married participants were the majority 295(98.3\%) while those not married accounted for $5(1.7 \%)$. As regards the parity of the mothers, majority of the mothers $142(47.3 \%)$ had $1-2$ previous deliveries while $78(26.0 \%)$ were carrying their first baby (Table 1). 
Table 1: Socio-Demographic Characteristics

\begin{tabular}{|c|c|c|}
\hline & Frequency & Percentage \\
\hline Mean Weight of the infants (Kg) & $5.8 \mathrm{SD}: 1.5$ & \\
\hline $\begin{array}{l}\text { Mean Age of the children } \\
\text { (months) }\end{array}$ & $3.06 \mathrm{SD}: 2.2$ & \\
\hline \multicolumn{3}{|l|}{ Age of child ( months) } \\
\hline$<1$ & 85 & 28.3 \\
\hline$-\quad 1-3$ & 125 & 41.7 \\
\hline - $\quad 4-6$ & 90 & 30.0 \\
\hline Age of mother (years) & 26.2 SD:5.0 & \\
\hline \multicolumn{3}{|l|}{ Mothers age group (Years) } \\
\hline$-\quad \leq 19$ & 13 & 4.3 \\
\hline - $\quad 20-24$ & 103 & 34.3 \\
\hline$-\quad 25-29$ & 112 & 37.3 \\
\hline - $\quad 30-34$ & 50 & 16.7 \\
\hline$-\quad \geq 35$ & 22 & 7.3 \\
\hline \multicolumn{3}{|l|}{ Mothers age group(Years) } \\
\hline$-\quad \leq 24$ & 116 & 38.7 \\
\hline$\geq 25$ & 184 & 61.3 \\
\hline \multicolumn{3}{|l|}{$\begin{array}{l}\text { Educational Qualification of } \\
\text { Mother }\end{array}$} \\
\hline Never being to School & 5 & 1.7 \\
\hline - $\quad$ Primary & 25 & 8.3 \\
\hline - $\quad$ Secondary & 165 & 55.0 \\
\hline Tertiary & 105 & 35.0 \\
\hline \multicolumn{3}{|l|}{ Religion } \\
\hline - Christianity & 291 & 97.0 \\
\hline Islam & 9 & 3.0 \\
\hline \multicolumn{3}{|l|}{ Mothers occupation } \\
\hline - $\quad$ Farmer & 20 & 6.7 \\
\hline - $\quad$ Gov't employee & 49 & 16.3 \\
\hline - $\quad$ Daily labour & 9 & 3.0 \\
\hline - $\quad$ Trader & 95 & 31.7 \\
\hline - $\quad$ Housewife & 69 & 23.0 \\
\hline - $\quad$ Skilled worker & 22 & 7.3 \\
\hline - $\quad$ Student & 30 & 10.0 \\
\hline Others & 6 & 2.0 \\
\hline \multicolumn{3}{|l|}{ Mothers marital status } \\
\hline - $\quad$ Currently Married & 295 & 98.3 \\
\hline - $\quad$ Not Married* & 5 & 1.7 \\
\hline \multicolumn{3}{|l|}{$\begin{array}{l}\text { Number of previous deliveries } \\
\text { before the present child }\end{array}$} \\
\hline - None & 78 & 26.0 \\
\hline$-1-2$ & 142 & 47.3 \\
\hline$-\quad \geq 3$ & 80 & 26.7 \\
\hline Total & 300 & 100 \\
\hline
\end{tabular}

* Include single(2), separated (2) and divorced (1)

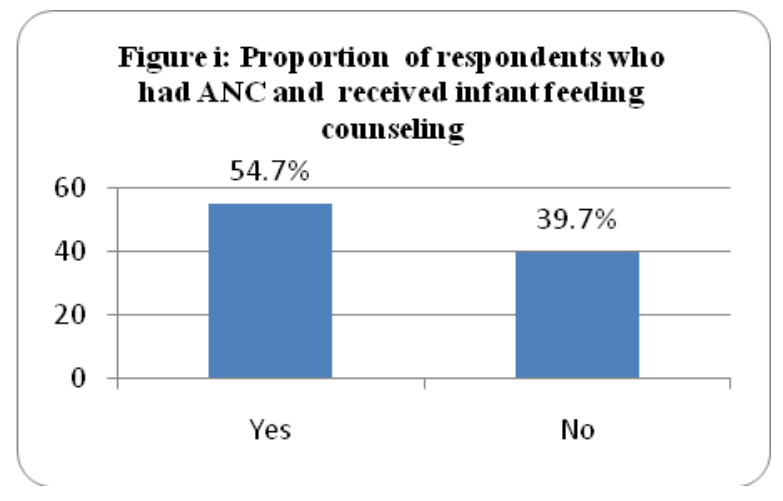

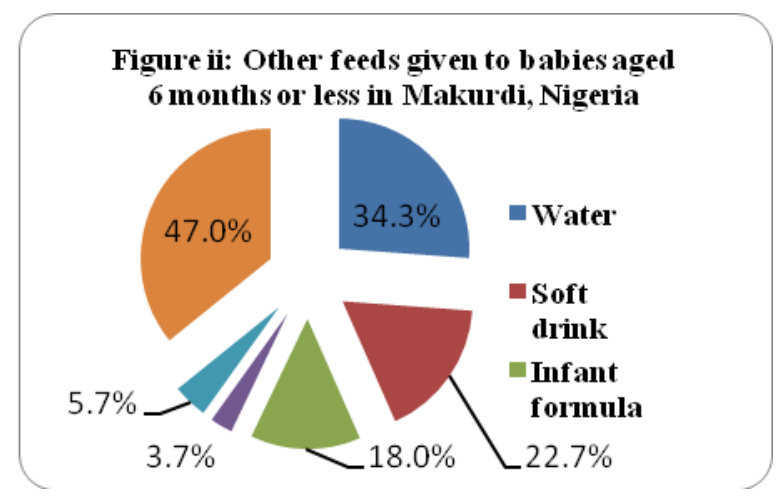

\section{Breast feeding practices}

Majority of the mothers 292(97.3\%) were currently breastfeeding while $8(2.7 \%)$ had stopped breastfeeding. Majority of the mothers 207(69.0\%) initiated breastfeeding within the first one hour of birth, while 93(31.0\%) initiated it after one hour.(Table 2) Among the mothers that did not initiate breastfeeding within the first one hour; $60(20 \%)$ indicated that the mother was sick, $13(4.3 \%)$ said the child was sick, $3(1.0 \%)$ admitted that the child was premature, $13(4.3 \%)$ said that it was because of cleaning up after birth, while $4(1.3 \%)$ did not advance any reason. (Figure iii). Less than half of the mothers $141(47.0 \%)$ were exclusively breastfeeding their infants, $159(53.0 \%)$ were not exclusively breastfeeding their infants. (Table 2)Among mothers that were not practicing exclusive breastfeeding, complimentary feeds were given. Majority of mothers 103(64.8\%) gave water, 68(42.8\%) administered soft drink, 54(34.0\%) gave infant formula, $11(6.9 \%)$ gave custard, while $17(10.7 \%)$ administered yam porridge, tea, fruit juice or liquid milk. (Figure ii)

Majority of the mothers, 243(81.0\%) had the intention of breastfeeding their infants for the period of 1323 months, while only $6(2.0 \%)$ had the intention of breastfeeding less than six months. About a third of the mothers $106(35.3 \%)$ received assistance to commence breastfeeding; while close to two-third $194(64.7 \%)$ did not receive the same. The mothers who were assisted to commence breastfeeding, majority of the assistance $58(19.3 \%)$ came from the Health Workers, while the Traditional Birth Attendant gave the least assistance $1(0.3 \%)$. (Table 2) More than half of the mothers $164(54.7 \%)$ had received infant feeding counseling during Ante Natal Clinic, while 119(39.7\%) indicated otherwise. (Table 2) 
Majority of the infants $60(70.6 \%)$ aged $0-1$ month were being exclusively breastfed. When compared to infants of other group; the relationship was found to be statistically significant $\left(\mathrm{X}^{2}=52.09, \mathrm{p}=<0.0000001\right)$. Majority of mothers 54(48.2\%) aged 25-29 were found to practice exclusive breastfeeding more when compared to other age group. This however, is not statistically significant $\left(\mathrm{X}^{2}=0.1887, \mathrm{p}=0.9958\right)$. Mothers that had one or more previous pregnancies practiced exclusively breastfeeding more than mothers that had no previous pregnancy. The relationship is statistically significant $\left(\mathrm{X}^{2}=4.838, \quad \mathrm{P}=0.02785\right)$. Majority of the mothers that had ANC 135(47.7\%) practiced exclusive breastfeeding more. However, the relationship with those that did not attend ANC was not statistically significant $\left(X^{2}=0.9913, p=0.3194\right)$ Majority of the mothers $79(48.2 \%)$ that had infant feeding counseling during ante-natal clinic practiced exclusive breastfeeding. The relationship with those that did not have infant feeding counseling was not statistically significant $\left(\mathrm{X}^{2}=0.03418 . \mathrm{p}=0.8533\right)$.

Table 2: Breast Feeding Practices

\begin{tabular}{|c|c|c|c|}
\hline & & Frequency & Percentage \\
\hline \multicolumn{4}{|c|}{ Currently breastfeeding } \\
\hline- & Yes & 292 & 97.3 \\
\hline- & No & 8 & 2.7 \\
\hline \multicolumn{4}{|c|}{$\begin{array}{l}\text { Breastfeeding Initiation after } \\
\text { delivery }\end{array}$} \\
\hline- & Within $1 \mathrm{hr}$ & 207 & 69.0 \\
\hline- & After $1 \mathrm{hr}$ & 93 & 31.0 \\
\hline \multicolumn{4}{|c|}{ Currently on EBF } \\
\hline- & Yes & 141 & 47.0 \\
\hline- & No & 159 & 53.0 \\
\hline \multicolumn{4}{|c|}{$\begin{array}{l}\text { Intended duration of } \\
\text { breastfeeding* }\end{array}$} \\
\hline- & $0-5$ mnths & 6 & 2.0 \\
\hline- & 6-11 mnths & 25 & 8.3 \\
\hline- & 12-23mnths & 243 & 81.0 \\
\hline & 24 mnths and above & 18 & 6.0 \\
\hline \multicolumn{4}{|c|}{$\begin{array}{l}\text { Received Assistance to } \\
\text { commence breastfeeding }\end{array}$} \\
\hline- & Yes & 106 & 35.3 \\
\hline- & No & 194 & 64.7 \\
\hline \multicolumn{4}{|c|}{ Who assisted in breastfeeding** } \\
\hline- & Health Worker & 58 & 19.3 \\
\hline- & Husband & 11 & 3.7 \\
\hline - & TBA & 1 & 0.3 \\
\hline- & Family member & 36 & 12.0 \\
\hline
\end{tabular}

Majority of the mothers $124(47.0 \%)$ that delivered at health facility practiced exclusive breastfeeding, However, the relation with those that delivered at TBA home was not statistically significant $\left(X^{2}=0.0008, p=0.9773\right)$. Even though the majority of mothers that had secondary school education and above practiced exclusive breastfeeding much more, the relationship with those that had primary education or less was not statistically significant $\left(\mathrm{X}^{2}=3.062, \mathrm{p}=0.08017\right)$. The mothers that were married 139(47.1\%) practiced exclusive breastfeeding more than the unmarried mothers $2(40 \%)$. However, the relationship was not statistically significant $\left(X^{2}=0.1, p=0.7518\right)$. Majority of infants $16(10.1 \%)$ that were not currently on exclusive breastfeeding had more episodes of diarrrhoea disease and when compared to those on exclusive breastfeeding, the relationship was statistically significant $\left(\mathrm{X}^{2}=4.9, \mathrm{p}=0.027\right)$. (Table 3 ).

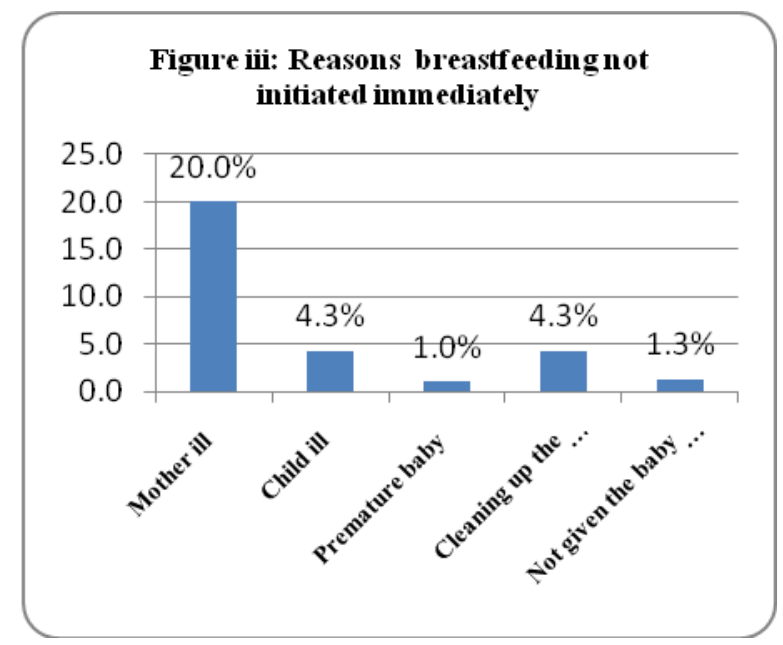


Table 3: Exclusive breastfeeding and other variables

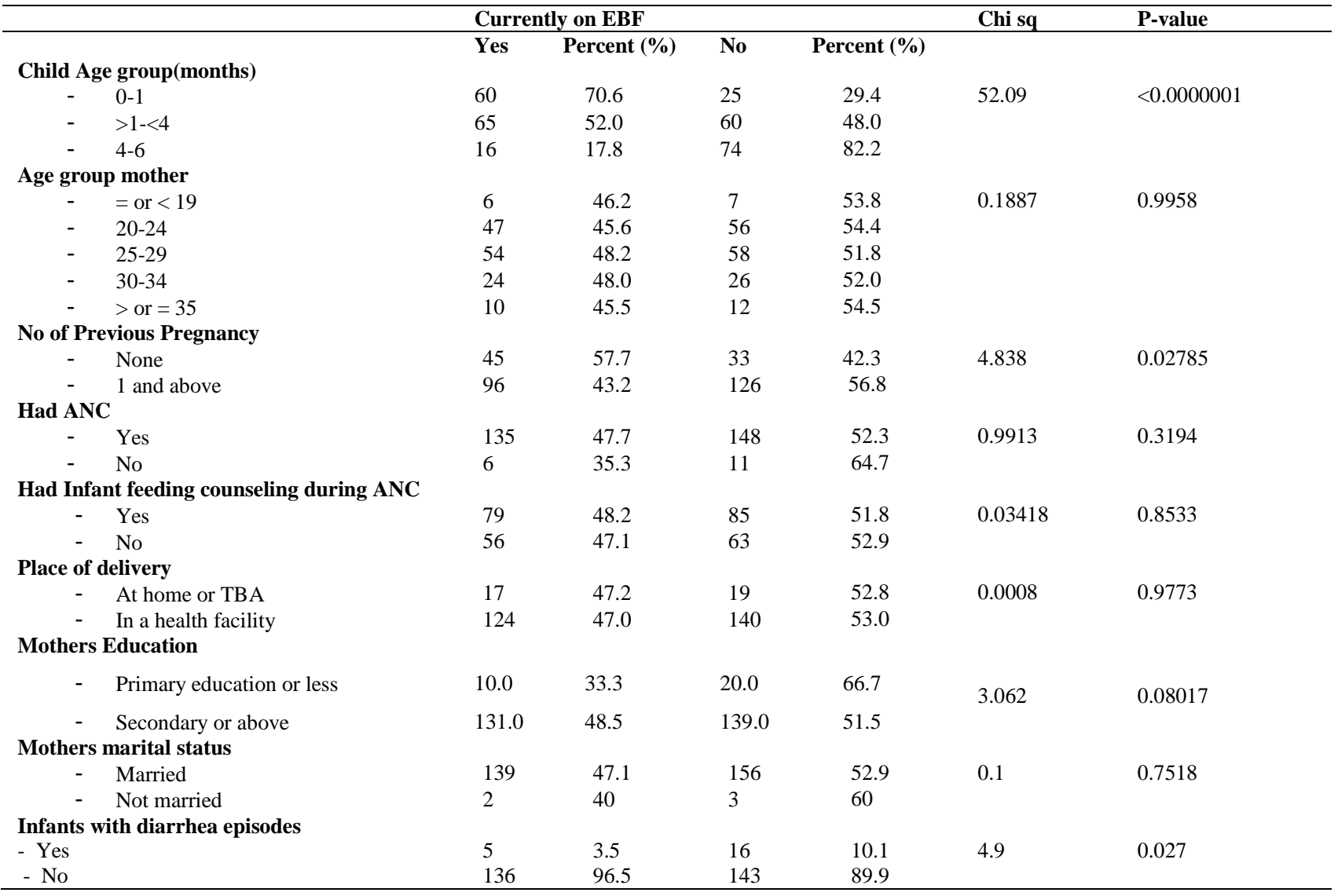

\section{Discussion}

This study found that $47.0 \%$ of the infants aged 0 6 months were being exclusively breastfed as at the time of the study. This figure is higher than what was reported in similar studies in some parts of Nigeria. For instance, $22.0 \%{ }^{26}$ was reported in Kano and $21.2 \%^{27}$ in Enugu State. Similarly, $22.8 \%,{ }^{28}$ and $22.9 \%^{24}$ were also reported in Uyo and Calabar respectively. However, the figure from the current study is similar to what was reported by Sadoh et al., amongst medical women. ${ }^{29}$ In other parts of Africa, some of the figures reported are similar to the one obtained in the current study. For example, $40.0 \%^{30}$ was reported in Bakwu town of Ghana and $49.0 \%^{31}$ in Ethiopia. Outside the shores of Africa varied figures have been documented. In SriLanka, the prevalence of exclusive breastfeeding was documented to be as high as $75 \%^{32}, 50.6 \%^{33}$ in Turkey and $43.1 \%$ in Malaysia ${ }^{34}$. This large variation in the prevalence of exclusive breastfeeding may be due to differences in methodology, population studied, cultural/traditional affiliation of the studied population as well as regional perceptions of exclusive breastfeeding practice.

Even though women in Benue State of Nigeria are known to have high breastfeeding culture as seen in the current study, this has not translated into practicing appropriate breastfeeding as recommended by WHO, UNICEF and other promoters of exclusive breastfeeding across the globe. The prevalence of exclusive breastfeeding reported in this study is below the WHO/UNICEF target ${ }^{17,18}$. In Makurdi City, some reasons could be advanced for this; many women in this part of Nigeria are well rooted in culture and tradition. As a result, exclusive breastfeeding may be seen as a western way of life which may take time to be fully embraced. Furthermore, the educational level of Makurdi women may be a factor. In Nigeria, women education is a challenge. The current study has observed that about two-third of the mothers had secondary school education or below. The experience of the authors is that, this level of education in makurdi may not be adequate to appropriately position the subjects to be a change agent. Therefore they 
would appear to be in a disadvantaged position when it comes to accessing and accepting information on new scientific findings. In addition, the low exclusive breastfeeding practice reported in this study has also brought to the fore the issues of ineffective grassroots public awareness.

The current study has also noted that more than half of the infants that were not exclusively being breastfed were given water and supplementary feeds. These include soft drink, infant formula, custard, tea, fruit juice, liquid milk and yam porridge. This is consistent with what was reported in previous studies ${ }^{35,36}$ This practice has long been discouraged by WHO and UNICEF.

Furthermore, for mothers who did not practice exclusive breastfeeding; some reasons have been advanced for their inability to do so. These reasons include mother's ill health, child's ill health, and having a premature baby. The reasons adduced here are not sufficient enough to stop exclusive breastfeeding. Experts in the field of Young Child Feeding Practices must do more in the area of public awareness with a view of correcting misconceptions among the people.

The present study further observed a strong association between exclusive breastfeeding and the occurrence of diarrhea in the infants. The infants that were exclusively breastfed had less episode of diarrhea when compared to those that were not exclusively breastfed. This fact has been established by many research findings ${ }^{37,38}$. For instance, it has been shown that early initiation of breastfeeding and exclusive breastfeeding are protective of diarrhoea in sub-Saharan African countries with high diarrhea mortality $^{37,38}$.

Similarly, the current study has also found a strong association between exclusive breastfeeding and the infants' age. The infants that were one month and below received more exclusive breastfeeding than the others. This is consistent with what has been reported in previous studies. ${ }^{28,39,40,41}$ The common concern expressed by the authors is the decline in the prevalence of exclusive breastfeeding with increasing age. The reason for this finding is not clear. What is however crystal clear to the authors is the increase in responsibilities with increasing mother's age in Benue State of Nigeria. These responsibilities could be social, spiritual or economic activities. The increasing involvement of mothers in these tasks with increasing age may pose a challenge to the practice of exclusive breastfeeding. Further study is suggested to enable researchers to look at this factor more carefully with a view of coming up with measures to addressing it.

A significant association was also found between exclusive breastfeeding mothers who have one or more previous pregnancies. They were noted to practice exclusive breastfeeding more than first time mothers. This finding is not consistent with the previous studies. In fact, the previous studies have established that multiparous women were less likely to initiate breastfeeding. This has led to the suggestion that multiparous women could be targeted for enhanced breastfeeding education and support. ${ }^{42}$ The reason for the conflicting findings in the current study is unclear. However, from the authors' experience over the years, it could be said that the first mothers in our environment could be easily pressured by friends and relations to engage in an unhealthy infant feeding practices. The researchers are of the considered opinion that further studies in this direction are advocated to resolve this conflict.

Furthermore, previous studies have established a positive association between exclusive breastfeeding and maternal higher education ${ }^{43,44}$, young maternal age $^{45,46}$, antenatal care attendance $e^{45,47,48}$ as well as hospital birth ${ }^{47,48}$. However, the current study has reported otherwise. The reason for the findings is not clear. It is also not clear if this kind of finding is peculiar to Makurdi women. However, further study is advised in this direction. The study could preferably be conducted in this particular location; preferably among similar subjects.

The limitations identified in the study include: the questionnaire used for this study was supposed to be self-reported diagnostic tools. Its interpretation to the respondents may reduce the accuracy of the responses. Secondly this is a health facility based study; as a result the actual percentage of the mothers that practiced exclusive breastfeeding in Makurdi (according to WHO criteria) could not be definitely established.

\section{Conclusion}

The prevalence of exclusive breastfeeding among infants aged 0-6 months was $47.0 \%$. The factors that were identified to be significantly associated with exclusive breastfeeding were occurrence of diarrhea, infants' age of 1month and below, and mothers with one or more previous pregnancies. These findings show that exclusive breastfeeding practice in Makurdi is above the national figure but below the World 
Health Organization target for infants that are six months and below. Efforts should be intensified to sustain and improve on the current figure through public awareness on the importance of exclusive breastfeeding. Similarly, the factors identified should be considered during intervention programs on Infants Feeding Practices.

\section{Acknowledgement}

The authors wish to acknowledge our subjects for providing the necessary information for this research work. We have also underlined the efforts of management of Benue State University Teaching Hospital, State Epidemiology Department and the Family Support Clinic for providing an enabling environment for this work.

\section{Conflict of Interests}

The authors declare no conflict of interests.

\section{References}

1. Jennifer B, Cynthia B, Kenji S and Robert EB. Child Health Epidemiology. Reference Group 2005. WHO estimates the causes of death in children. Lancet 2005;365:1147-1152

2. WHO/UNICEF. Global Strategy for infant and young child feeding. WHO Genera. 2003: 5-10.

3. Jones G, Steketee RW, Black RE, Bhutta ZA and Morris SS Bellagio Child Survival Study Group. How many child deaths can we prevent this year? Lancet. 2003;362:65-71.

4. Uchendo UO, IkefunaAN andEmodi IJ. Factors Associated with Exclusive Breastfeeding among mothers seen at the University of Nigeria Teaching Hospital. SA Journal of Child Health 2009; 3:14-19.

5. James CS "Breastfeeding" Nutritional and Well being A-Z 2004 Available from http://www.encyclopedia.com Accessed on $02 / 12 / 2016$.

6. United States Department of Health and Human Services, Office of Women Health (2000) HHS Blueprint for action on breastfeeding, Washington DC US. Printing Office.

7. Horta BL andVictora CG. Long-term effects of breastfeeding: a systematic review. Geneva: World Health Organization; $2013 \quad$ (http://apps.who.int/iris/ bitstream/10665/79198/1/9789241505307_eng.pdf, accessed 7 October 2016).

8. Black RE, Victora CG, Walker SP, Bhutta ZA, Christian P, de Onis $M$ et al. Maternal and child undernutrition and overweight in low-income and middle-income countries. Lancet. 2013;382:427-51. doi:10.1016/S01406736(13)60937-X.

9. World Health Organization. World Health Statistics 2013 (www.who.int/ gho/publications/world_health_statistics/2013/en/, accessed 7 October 2014).

10. Solomon A andZemene T. Risk Factors for severe acute malnutrition in children under the age of five years. A CaseControl study. Ethiop. J. Health Development. 2008; 22: 21-25
11. National Population Commission (NPC) Nigeria. Nigerian Demographic and Health Survey, 2004 Report.

12. National Population Commission (NPC) Nigeria, and ICF Macro. Nigeria Demographic and Health Survey 2008, Abuja. 2009 Report.

13. UNICEF 2011. At a glance Ghana: Available atwww.unicef.org/infobycountry/ghana_statistics.htm. Accesses on 08/01/2017

14. Ekure EN, Anita-Obong OE, Udo JJ, Edet EE. Maternal Exclusive breastfeeding Practice in Calabar, Nigeria: Some related social characteristics:. Niger J. Clin Pract 2003:6Abstract

15. Ifeoma E, Clement Eand John OC. Breastfeeding Practices in Onitsha South Eastern Nigeria-2 years after Baby Friendly Initiative. Trop.J.of Med.Res.2004;8:26-31.

16. Kingsley EA, Michael JO, Justice IO, Sunday MO. Determinants of exclusive breastfeeding in Nigeria. BMC Pregnancy and Childbirth 2011;11.

17. UNICEF. Breastfeeding on the worldwide agenda: findings from a landscape analysis on political commitment to protect, promote and support breastfeeding. New York: UNICEF; 2013 (http://www.unicef.org/eapro/breastfeeding_on_ worldwide_agenda.pdf, accessed 7 October 2016). 8.

18. World Health Organization.Essential nutrition actions: improving maternal, newborn, infant and young child health and nutrition. Geneva: World Health Organization; 2013 (http://www.who.int/nutrition/publications/infantfeeding/esse ntial_nutrition_actions/en/, accessed 7 October 2014).

19. Amin T, Hablus $\mathrm{H}$ and $\mathrm{Al}$ Qader AA. Determinants of initiation and exclusivity of breastfeeding in Al Hassa Saudi Arabia. Breastfeeding Medicine 2011;6:59-68.

20. Thulier D and Mercer J. Variables associated with breastfeeding duration. Journal of Obstetrics and Gynaecology and Neonatal Nursing 2009;38:259-268.

21. Narayan $\mathrm{S}$, Natarajan $\mathrm{N}$ andBawa $\mathrm{KS}$. Maternal and neonatal factors adversely affecting breastfeeding in the perinatal period. 2005;61

22. Cheika J, Naushad MK and Maleika HK. Analyzing the factors influencing exclusive breastfeeding using the generalized poisson regression model. International Journal of Computational and Mathematical Sciences 2009;3:301303.

23. Liqian Q, Yun Z, Cohn WB, Andy HLand Xing X. Initiation of breastfeeding and prevalence of exclusive breastfeeding at hospital discharge in urban, suburban and rural areas of Zhejiang, China. International Breastfeeding Journal 2009; $4: 1-7$

24. Ekure EN, Antia-Obong OE, Udo JJ, Edet EE. Maternal Exclusive Breastfeeding Practice in Calabar, Nigeria: some related social characteristics. Nigerian Journal of Clinical Practice 2003; 6:Abstract.

25. World Health Organization Sample Size Determination. A user's Manual. WHO/HST/ESM/86.1

26. Muchina EN and Waithaka N. Relationship Between Breastfeeding Practices and Nutritional Status of Children Aged 0-24 months in Nairobi, Kenya. AJAND 2010; 10:2359 2380 .

27. Sebanjo IO and Adeodu OO. Risk Factors for Malnutrition among rural Nigerian Children. Asia Pacific J. ClinNutr. 2006; 15:491-495 
28. Egwuda, L. Pattern of rates of exclusive breastfeeding in the Niger Delta region of Nigeria. Int $\mathrm{J}$ of Med Sci Public Health.2015;4:878-882

29. Sadoh AE, Sadoh WE andOniyelu P. Breastfeeding practice among medical women in Nigeria. Nigerian Medical Journal 2011;52:7-12.

30. UNICEF. Breastfeeding just 10 steps-The Baby Friendly Way; Press release 2010.60

31. Tewodros A, Jema H, Dereje H. Determinants of Exclusive Breastfeeding Practices in Ethiopia. Ethio. J. Health Dev. 2009; 23:13-19.

32. Sunneth BA, Thilinic CA, Avanthic C, Exclusive breastfeeding in Srilanka: Problems of interpretation of reported rates. International Breastfeeding Journal 2009;4:14.

33. Karacham Z. Factors affecting exclusive breastfeeding of healthy babies aged zero to four months. A community based study of Turkish women. J ClinNurs.2008;17:341-349.

34. Kok LT. Factors associated with exclusive breastfeeding among infants under six months of age in Peninsular Malaysia. International Breastfeeding Journal 2011;6:2

35. Supplementary feeding in early infancy. Available at: http://www.rand.org/pubs/research

36. Anogo KM, Ameh DA, Ibrahim S and Solomon SD. Infant Feeding Practices and Nutritional status of Children in North East. Science alert. Available at: http:wwwscialert.net/fulltext

37. Ogbo FA, Agho K, Ogeleka P, Woolfenden S, Page A, Eastwood J, et al. (2017) Infant feeding practices and diarrhoea in sub-Saharan African countries with high diarrhoea mortality. PLoS ONE 12(2): e0171792. doi:10.1371/journal.pone.0171792

38. Exclusive breastfeeding prevents childhood death-UNICEF report. Available at: http://nigeriapoliticsonline.com. Accessed on 20/02/2017

39. Ruowei L, Cynthia O, Carol B, Cathleen G and Lawrence G. Prevalence of exclusive breastfeeding among U.S infants. The third National Health and Nutritional Examination Survey(Phase II 1991-1994). American Journal of Public Health 2002,92: 1107-1110.

40. Jose MCC, Graciela N, Lilian B, Ana MM, Amando GD. Maternal and perinatal factors influencing the duration of first six months of life. Journal of Human Lactation 2003;19:136-144.

41. Pakom 1, Budsaba W, Chadakarn $\mathrm{P}$ andSumonmalM. Prevalence of exclusive breastfeeding at 3,4, 6 months in Bankok. J Med Assoc Thai 2008; 91: 962-967.

42. Tori S, Christopher BP, Joan LB and Victoria LH, Breastfeeding Practices Among First-Time Mothers and Across Multiple Pregnancies. Matern Child Health J, 2012;16(8):1665-1671

43. Li L, Li S, Ali M and Ushijima $\mathrm{H}$. Feeding practice of infants and their correlates in urban area of Beinjing, China. Pediatrics International 2003;45:400-406.

44. Hana N, Agnes G, Mestin B and Barbara JS. Factors related to exclusive breastfeeding and dietary diversity of complementary foods. A case study in Amhara region of Ethiopia. The Journal of the Federation Of American Societies for Experimental Biology. Available at http://www.fasebj.org/cgi/content/meeting/abstract. Accessed on $15 / 04 / 2010$.

45. Cheika J, Naushad MK andMaleika HK. Analyzing the factors influencing exclusive breastfeeding using the generalized poisson regression model. International Journal of Computational and Mathematical Sciences 2009;3:301303.

46. Livinus E, Etukumana EA andTerhemen JT. Sociodemographic factors affecting exclusive breastfeeding in south-south Nigeria. Asian Pac.J. Health Sci.,2015:2(3):94101

47. Leung Eyl, Au Kya, Cheng SSW, Koksy, LuiHk and Wong Wcw. Practice of Breastfeeding and Factors that Affect Breastfeeding in Hong Kong. Hong Kong Med.Journal. 2006;12:432-435.

48. Ukegbu AU, Ukegbu PO, Onyeonoro UU and Ubajaku CF. Determinants of breastfeeding patterns among mothers in Anambra State, Nigeria. South African Journal of Child Health, 2010;5: 